\title{
Saving a dog with dexamethasone
}

\author{
Yavor Pindev ${ }^{1}$, Zahariy Krastev ${ }^{2}$
}

1. Veterinary medical establishment Category I, No. 2292123;

2. University Hospital St. Ivan Rilski Sofia;

\begin{abstract}
We present a life-threatening anaemia in an eight-month-old dog, of the pug breed (haemoglobin $43 \mathrm{~g} /$ L), accompanied by splenomegaly. The condition was quickly overcome with a 3-day course of dexamethasone $1 \mathrm{mg} / \mathrm{kg} /$ day. Pulse therapy with corticosteroids was discussed.
\end{abstract}

Keywords: dog, haemolysis, dexamethasone, pulse

\section{Clinical presentation}

On 27.10. 2017 a patient - dog, Rocco L.P., of the pug breed, sex M, age $8 \mathrm{~m}, 8 \mathrm{~kg}$ body weight was brought to the clinic presenting with a history of general weakness, falls, lethargy, and lack of appetite.

General condition: This is a young dog with signs of moderate dehydration, pale mucous membranes and general weakness, with delayed reflexes.

The clinical examination found: Inner body temperature 36.5 degrees; fading to white conjunctives, pale oral and tongue mucosa, reduced skin turgor, lack of appetite, with no defecation and pissing, physiological vesicular breathing, without stridor, difficult cough reflex; heart - 68 beats / min., physiological arrhythmia, clear heart tones, no abnormal noises. Abdominal cavity - no auscultative and palpatory abnormalities. Sex organs - no peculiarities. Anus and perianal area - no abnormalities.

Limbs - cool to cold - no visible orthopaedic or traumatic changes. Lymph nodes were found just around the mandible, with the size of a small cherry. 
Immunoprophylaxis - the patient is given a three-stage vaccination regimen at 42, 60 and 90 days of age against Parvovirus, Ghana, Adenovirosis, Rupert Hepatitis, Parainfluenza, Leptospirosis and Rabies.

Rapid tests: Anaplasma spp. Ab test kit - negative at 5th and 10th min; Erlicia canis Ab test kit - negative at 5th and 10th minute.

Reasons for conducting the tests - the prevalence of anaplasmosis, babesiosis, erlichiosis and heartworm disease on the territory of the country and in Sofia-city region in general.

Laboratory tests: urea 7,9 mmol/L, creatinine $59 \mathrm{mmol} / \mathrm{L}$, ASAT $14 \mathrm{U} / \mathrm{L}$, ALAT $24 \mathrm{U} / \mathrm{L}$, Alc Ph 74 U/L.

The results of blood counts are presented in Table 1.

Table 1. Complete blood count in a dog with severe anaemia treated with pulse dexamethasone

\begin{tabular}{|c|c|c|c|c|c|c|c|c|c|c|}
\hline test & RR & $\begin{array}{r}27 \text { oct } \\
2017\end{array}$ & $\begin{array}{l}31 \text { oct } \\
2017\end{array}$ & $\begin{array}{l}4 \text { nov } \\
2017\end{array}$ & $\begin{array}{l}6 \text { nov } \\
2017\end{array}$ & $\begin{array}{l}15 \text { nov } \\
2017\end{array}$ & $\begin{array}{l}28 \text { nov } \\
2017\end{array}$ & $\begin{array}{l}15 \mathrm{dec} \\
2017\end{array}$ & $\begin{array}{l}07 \mathrm{fev} \\
2018\end{array}$ & $\begin{array}{l}16 \mathrm{apr} \\
2018\end{array}$ \\
\hline WBC & $6.0-17.0 \times 10^{\wedge} 9 / \mathrm{L}$ & 17.98 & 32 & 46.9 & 38.6 & 11.9 & 7.9 & 11.1 & 14.1 & 16.9 \\
\hline Lymph \# & $0.8-5.1 \times 10^{\wedge} 9 / \mathrm{L}$ & 1.46 & 11.6 & 14.9 & 6.8 & 1.8 & 2.2 & 3 & 3.3 & 4,1 \\
\hline Mon \# & $0.0-1.8 \times 10^{\wedge} 9 / \mathrm{L}$ & 1 & 2.4 & 3.7 & 2 & 0.7 & 0.6 & 0.5 & 0.8 & 0.7 \\
\hline Gran \# & $4-12.6 \times 10^{\wedge} 9 / \mathrm{L}$ & 15.52 & 18 & 28.3 & 29.8 & 9.4 & 5.1 & 7 & 10 & 12.1 \\
\hline RBC & $5-8.5 \times 10^{\wedge} 12 / L$ & 2.46 & 1.65 & 2.44 & 3.48 & 4.05 & 4.83 & 5.04 & 5.57 & 5.8 \\
\hline HBG & $110-190 \mathrm{~g} / \mathrm{L}$ & 50 & 43 & 76 & 103 & 113 & 128 & 132 & 144 & 141 \\
\hline HTC & $39-56$ & 16,5 & 13.9 & 24.2 & 31 & 35.2 & 40.7 & 0.412 & 42.7 & 43.6 \\
\hline MCV & $62.0-72.0 \mathrm{fL}$ & 67 & 84.4 & 99.2 & 91.2 & 87.1 & 84.3 & 81.8 & 76.8 & 75.3 \\
\hline PLT & $117-460 \times 10^{\wedge} 9 / \mathrm{L}$ & 180 & 295 & 283 & 437 & 434 & 825 & 279 & 373 & 306 \\
\hline $\mathrm{LDH}$ & $20-500 \mathrm{U} / \mathrm{l}$ & & & 2000 & 640 & 620 & 595 & 236 & 20 & 20 \\
\hline
\end{tabular}

\section{Clinical decision}

Based on the clinical examination and clinical laboratory tests, anaemia was confirmed, hepatoencephalopathy (history of seizures), uremic syndrome and renal dysfunction (creatinine, urea), haemorrhagic conditions (platelets) were rejected. 
Due to the fact that the general condition of the animal has deteriorated rapidly (history) and regardless of the results of the blood counts, the possibility of an acute infectious disease of congenital or vector origin, decompensated malaise or intoxication is not excluded.

Treatment regimen was given: Linkomicin $22 \mathrm{mg}$, i.m./24h for 5 days; Maltofer $-1 / 4$ tab. twice a day for 7 days; Neurobex - 1 tab. daily for 7 days; Vit C $100 \mathrm{mg}-1$ tab. in the morning and in the evening for 7 days, Serum glucosae $200 \mathrm{ml}$. sc. daily; and a scheduled review for October 31, 2017.

\section{Change of clinical decision}

\section{Checklist 31.10.2017}

Anamnesis obtained from the owners: The treatment course was performed according to the planned schedule, the general condition of the animal had not changed, general weakness and lethargy had exacerbated, no "seizures" had been observed.

The results of haematology (Table 1 ) showed not only a lack of good outcome of the therapy but also a worsening and deepening of the pathological changes.

Additionally, a blood smear was prepared (fig.1, 2). The presence of erythrocytes of different sizes was found, in some of them cytoplasmic inclusions (possibly artefacts), but Babesia spp. were not found.

However, single erythrocyte cells resembled target or colonic cells, which directed us to examine the possibility of developing immune haemolytic anaemia. No aggregated erythrocytes were found in the smear.

Single erythrocyte cells however, resembled target or cocardial cells. We discussed immune haemolytic anaemia (IHM). No aggregated erythrocytes were found in the smear.

Figure 1. Anisocytosis

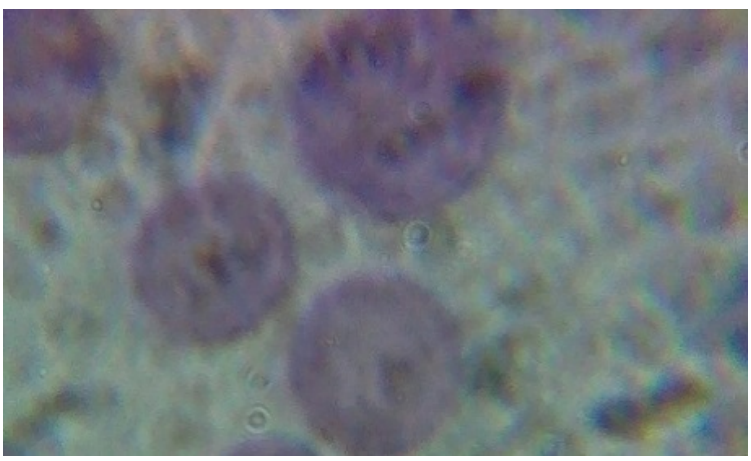


Figure 2 "Cocarde“ red blood cells

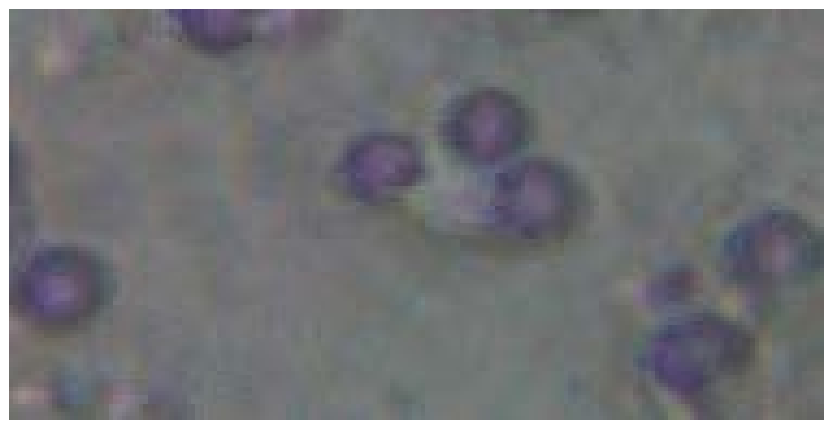

\section{Echography.}

The ultrasound examination of the abdominal cavity of the patient established:

Bladder and kidney - no deviation from normal echographic aspect and echogenicity, clearly distinguishable cortex and kidney medulla. No images suggestive of sediment or uroliths.

Liver - normal homogeneous echogenicity, clearly visible liver blood vessels, egg-shaped gall bladder and about $4 \mathrm{~cm}$ in diameter.

Spleen - Increased size - splenomegaly.

\section{Change of treatment. Pulse with dexamethasone}

The therapy scheme is shown in Table 2 . A three-day pulse with a dexamethasone $1 \mathrm{mg} / \mathrm{kg} / \mathrm{day}$

Table 2. Medical treatment of a dog with severe anaemic syndrome.

\begin{tabular}{|l|c|c|c|c|c|}
\hline Drug & $\begin{array}{c}31 \text { oct } \\
2017\end{array}$ & $\begin{array}{c}4 \text { nov } \\
2017\end{array}$ & 6 nov 2017 & $\begin{array}{c}15 \mathrm{nov} \\
2017\end{array}$ & $\begin{array}{c}28 \mathrm{nov} \\
2017\end{array}$ \\
\hline Dexamethasone & $1 \mathrm{mg} / \mathrm{kg} / \mathrm{d}$ & & & $\begin{array}{c}1 \mathrm{mg} \\
\text { every } \\
\text { every } 3 \\
\text { days }\end{array}$ & $\begin{array}{c}3 \text { days } \\
4 \text { times }\end{array}$ \\
\hline Maltofer & $1 / 4 / \mathrm{tab} / \mathrm{d}$. & $1 / 4 / \mathrm{tab} / \mathrm{d}$. & & & \\
\hline Famotidine & $10 \mathrm{mg} / \mathrm{d}$. & $10 \mathrm{mg} / \mathrm{d}$. & & & \\
\hline Cefsil & $250 \mathrm{mg} / \mathrm{d}$ & $250 \mathrm{mg} / \mathrm{d}$ & & & \\
\hline Folic acid & & & $10 \mathrm{mg} / \mathrm{d}$. & & \\
\hline
\end{tabular}




\begin{tabular}{|l|l|c|l|l|}
\hline Erythropoietin & $\begin{array}{c}20 \text { Ul/kg } \\
\text { Twice weekly }\end{array}$ & & & \\
\hline
\end{tabular}

\section{Checklist on 04.11.2017}

The animal had an improvement in appetite, vitality and temperament. The echography showed a noticeable reduction in the size of the spleen, which was attributed to dexamethasone.

Blood glucose measurement was performed on the patient because of polydipsia noticed by the owner. The result was $4.9 \mathrm{mmol} / \mathrm{L}$. The white blood cells count was disturbing. The increase in red blood cells and haemoglobin were encouraging. A biochemical analysis of CRP and LDH was also performed, the values were respectively CRP - $60 \mathrm{mg} / \mathrm{L}$ and LDH $2000 \mathrm{U} / \mathrm{L}$

The treatment scheme was preserved.

\section{Checklist 6/11/2017:}

From the history - a significant improvement in appetite, temperament and vitality. For the first time, some coloration of the conjunctivae was detected. The results showed some reduction in leucocytosis, erythrocyte and haemoglobin growth, decreased CRP, and reduction of LDH levels. Control echography re-confirmed the reduction of splenomegaly.

\section{Therapeutic success}

Control review from 15.11.2017: General condition - satisfactory, appetite, temperament - satisfactory. Normalized haematological parameters. Detectable residue condition of slight haemolysis.

Control review on 29.11.2017 - The tendency for improvement in the general condition of the dog is maintained, corrections in the treatment scheme are not necessary.

Check review 15.12.2017 - General Condition - Good. Mucous membranes - pink. Appetite, temperament, general condition - excellent. Treatment continued until 30.12.2017. Dexamethasone $0.5 \mathrm{mg}$ every 3 days 4 times.

Control review 07.02.2018 - Clinically robust.

Checklist 16.04.2018 - Clinically healthy, restored clinical, vital and behavioural indicators. No treatment is performed.

\section{Discussion}

Based on the clinical examination and clinical laboratory tests, anaemia was confirmed, hepatoencephalopathy (history of seizures), uremic syndrome and renal dysfunction (creatinine, urea), and haemorrhagic conditions (platelets) were rejected.

Due to the fact that the general condition of the animal had deteriorated rapidly (history) and regardless of the results, the possibility of an acute infectious disease of congenital or vector origin, decompensated malaise or intoxication were not excluded. The increased spreading of the vector diseases anaplasmosis, 
babesiosis, erlichiosis and cardiomyopathy on the territory of the country and in particular the Sofia region imposed its demand in this critical condition.

Critical overall weakness and lethargy without "seizures" and the extra decrease of haemoglobin to lifecritical values of $43 \mathrm{~g} / \mathrm{L}$ challenged us to look for other explanations - erythrocyte morphology and search for blood parasites. The presence of erythrocytes of different sizes was found, in some of them cytoplasmic inclusions (possibly artefacts) were detected, but no Babesia spp. were found. High doses of corticoids "pulse" Dexamethasone $1 \mathrm{mg} / \mathrm{kg} /$ day for three days provided a haemoglobin of $76 \mathrm{~g} / \mathrm{L}$ and rescued the dog. The dramatic increase in the number of leukocytes was associated with dexamethasone application. LDH was 4 times the norm. After 25 days haemoglobin was completely normal.

The difference in the size of erythrocytes in young animals and dogs in particular is normal for about $10 \%$ of the cells. Juvenile anisocytosis was not a definite explication for the morphological changes in erythrocytes. Single erythrocytes resembled target or cocardial cells, which directed us to examine the possibility of haemolysis, including immune haemolytic anaemia. No aggregated erythrocytes were found in the smear. Haemolysis explained splenomegaly.

The leader in immune haemolytic anaemia therapy is immunosuppression, and the most commonly used immunosuppressants are corticosteroids. In the literature, prednisone at a dose of $1-2 \mathrm{mg} / \mathrm{kg}$ at 48 hours is indicated first.

High dose corticosteroid; Dexamethasone; and Methylprednisolone Glucocorticoids have been used for the management of inflammatory diseases for the past 50 years. The first reported use of high dose intravenous corticosteroids was in 1969 when it was used to successfully prevent kidney allograft rejection. High dose i.v. corticosteroid therapy or "pulse" steroid therapy was first used for the treatment of acute rejection after kidney transplantation in 1973 for the treatment of lupus nephritis in 1976 and in steroid resistant nephrotic syndrome later. However, there are considerable variations in the dose, number, timing and duration of administration of high dose i.v. corticosteroids. Also, despite more than three decades of use, there is little clarity on the mechanism of action, magnitude of benefits and adverse effects (1).

Dexamethasone is used for twice weekly $5 \mathrm{mg}$ oral pulse for six months in a human, dose of $5 \mathrm{mg}$ in adults and $2.5 \mathrm{mg}$ to $3.5 \mathrm{mg}$ in children. Side effects of corticosteroids were frequent (27\%), but were mild (2).

High-dose glucocorticoid pulse therapy, an alternative protocol used for pemphigus in humans, has been shown to provide rapid improvement in dogs with pemphigus foliaceus and vulgaris. The authors suggest several benefits associated with oral glucocorticoid pulse therapy, such as a higher proportion of dogs achieving complete remission during the first 3 months, and a lower mean maximum oral glucocorticoid dose given between pulses and minimal adverse drug events (3).

High-dose pulse therapy with methylprednisolone may cause fulminant hepatic failure. Dexamethasone pulse therapy can be considered as an alternative to pulse methylprednisolone therapy with a better effect on the reduction of exophthalmos (4).

A four-day course of high-dose dexamethasone (40 $\mathrm{mg}$ per day) is an effective initial therapy for adults with immune thrombocytopenic purpura (5). 
We chose the intramuscular route of corticoid administration because of the critical condition and good compliance.

\section{Conclusion}

Life-threatening haemolysis may be successfully overcome with three days of dexamethasone $1 \mathrm{mg} / \mathrm{kg}$. The very high dose we used was well-fed and there is no recurrence in the subsequent 9 months.

\section{References}

1. Sinha A, Bagga A. Pulse Steroid Therapy. Indian J Pediatr 2008; 75 (10): 1057-1066.

2. Sharma VK, Gupta S.Twice weekly $5 \mathrm{mg}$ dexamethasone oral pulse in the treatment of extensive alopecia areata. J Dermatol. 1999 Sep; 26 (9): 562-565.

3. Bizikova P, Olivry T. Oral glucocorticoid pulse therapy for induction of treatment of canine pemphigus foliaceus - a comparative study. Vet Dermatol. 2015;26(5):354-358.

4. Philip R, Saran S, Gutch $M$ et al. Pulse dexamethasone therapy versus pulse methylprednisolone treatment for Graves's ophthalmopathy. Indian J Endocrinol Metab. 2013; 17 (Suppl1): 157-159.

5. Cheng Y, Wong RS, Soo YO et al. Initial Treatment of Immune Thrombocytopenic Purpura with High-Dose Dexamethasone. N Engl J Med. 2003; 349 (9): 831-836.

\section{Corresponding author:}

Zahariy Krastev, University Hospital St. Ivan Rilski Sofia, zahkrastev@gmail.com 